\title{
Does South Africa need a national clinical trials support unit?
}

\author{
N Siegfried, J Volmink, A Dhansay
}

Background. No national South African institution provides a coherent suite of support, available skills and training for clinicians wishing to conduct randomised controlled trials (RCTs) in the public sector. We report on a study to assess the need for establishing a national South African Clinical Trials Support Unit.

Objectives. To determine the need for additional training and support for conduct of RCTs within South African institutions; identify challenges facing institutions conducting RCTs; and provide recommendations for enhancing trial conduct within South African public institutions.

Design. Key informant interviews of senior decision-makers at institutions with a stake in the South African public sector clinical trials research environment.

Results. Trial conduct in South Africa faces many challenges, including lack of dedicated funding, the burden on clinical load, and lengthy approval processes. Strengths include the high burden of disease and the prevalence of treatmentnaïve patients. Participants expressed a significant need for a national initiative to support and enhance the conduct of public sector RCTs. Research methods training and statistical support were viewed as key. There was a broad range of views regarding the structure and focus of such an initiative, but there was agreement that the national government should provide specific funding for this purpose.

Conclusions. Stakeholders generally support the establishment of a national clinical trials support initiative. Consideration must be given to the sustainability of such an initiative, in terms of funding, staffing, expected research outputs and permanence of location.

S Afr Med J 2010; 100: 521-524.
The randomised controlled trial (RCT) is the gold standard for evaluating the effects of health care interventions. ${ }^{1}$ Therefore, South African health policy and clinical guidelines should be based on well-conducted RCTs that ideally are conducted within the country to ensure local applicability.

Conducting RCTs in South Africa faces numerous obstacles. Specialist training in the universities traditionally focuses on clinical experience and skills accrual, and lacks a research focus. Downscaled tertiary service units struggle to remain academically active, ${ }^{2}$ reducing the opportunities for local clinicians to acquire the epidemiological and statistical skills for conducting RCTs. Health professionals interested in clinical research may have to migrate to develop these skills. Opportunities to then practise those skills may only exist overseas, contributing to the professional brain drain. ${ }^{3}$

When research funding is not available from local sources, researchers become dependent on funds from donor agencies or the drug industry, potentially deflecting priorities away from local needs. ${ }^{4}$ African governments have committed to spend $2 \%$ of their health budgets on research. ${ }^{5}$ In 2008/2009,

South African Cochrane Centre and MRC Clinical Trials Initiative, Medical Research Council, Cape Town

Nandi Siegfried, MB ChB, MPH (Hons), FCPHM (SA), DPhil (Oxon)

South African Cochrane Centre and MRC Clinical Trials Initiative, Medical Research Council, and Faculty of Health Sciences, Stellenbosch University Jimmy Volmink, BSc, MB ChB, MPH, DPhil (Oxon)

Office of the Vice-President: Research, Medical Research Council, and MRC Clinical Trials Initiative, Medical Research Council

Ali Dhansay, MB ChB, DCH, MMed (Paed), FCPaed the South African Medical Research Council (MRC) received far short of the promised 2\% from the national Department of Health (DoH), even if National Research Foundation monies are added to this. ${ }^{6}$ The MRC is reported to be chronically underfunded despite its mandate to maintain and develop clinical research capacity. ${ }^{2}$

RCTs require intensive planning, co-ordination, expertise ${ }^{7}$ and sufficient funding. There is no national institution providing a coherent suite of support, available skills and training for clinicians wishing to conduct trials in the public sector. In many countries, clinical trials support units offer such support to clinicians and researchers in a variety of settings. ${ }^{8}$ The MRC consequently funded a feasibility study to assess the need for establishing a national South African Clinical Trials Support Unit. We report on a component of the study comprising key informant interviews of national decisionmakers.

\section{Objectives}

Our objective was to determine the need for additional training and support for conducting randomised clinical trials within South African institutions; identify challenges facing institutions conducting randomised clinical trials; and provide recommendations for enhancing trial conduct within South African public institutions.

\section{Methods}

\section{Sampling}

The study was qualitative, comprising key informant interviews. Sampling was purposive: the research team identified senior decision-makers at stakeholder institutions; during their interviews, participants were asked to suggest additional key informants to provide contributory insights 
('snow-balling'). The number of interviews was considered sufficient when participants from at least one of all the key institutions had been interviewed and no new information was forthcoming. We anticipated that a minimum of 20 interviews would be required to ensure inclusion of all universities, government organisations and non-government organisations active in the conduct, use or funding of trials.

\section{Data collection and management}

The study received ethics approval from the MRC Ethics Committee in February 2008. The principal investigator (NS) conducted the interviews between May and August 2008. Interviews were semi-structured and open-ended, made use of probes to explore key areas, and took approximately 45 minutes each. Participants were encouraged to base their answers on experience in their representative institutions and on their personal knowledge of the South African clinical trials landscape. They were audio-recorded with the interviewee's permission after signing an informed consent form. An individual unaware of the identity of the interviewee transcribed the interviews. Transcripts and identifying material were accessible only to the principal investigator.

\section{Data analysis}

The transcripts of the in-depth interviews were reviewed, and a code list of the emergent themes and sub-themes was generated for analysis. Participants were emailed the preliminary analysis for additional comment. The data are presented as frequencies, and illustrative quotations appear in italics.

\section{Results}

\section{Characteristics of key informants}

Sixteen interviews (15 face-to-face and 1 telephonic) were conducted; 14 were conducted with a single informant, 1 was conducted with 2 informants, and 1 with 3 informants. The views of 19 senior individuals from 14 institutions were thus elicited. At 7 of the 8 South African universities with clinical faculties of health sciences, interviews were conducted at the level of a dean or equivalent. The representatives from other institutions were all at senior management levels. Two key informants who agreed to be interviewed subsequently were not able to participate in the interview. The Medicines Control Council (MCC) was invited to participate, but no representative was forthcoming.

\section{Institutional trial experience}

Of the 10 institutions which reported conducting clinical trials, 9 believed that they were experienced in trial conduct, with 2 reporting that the level of trial experience was variable across the institution. At the time of the interview, 3 institutions were conducting over 50 trials, 3 were conducting between 10 and 50 trials, and 4 were conducting less than 10 trials. Respondents whose institutions did not conduct trials reported using trial results to determine policies or were involved in administering trial research training, or funding.

\section{Trial funding}

All informants reported funding sources as broad-based, including a combination of institutional support and grants, international agencies, the MRC and pharmaceutical industry. Strong themes that emerged were: (i) lack of funding for investigator-driven (also known as self-initiated) trials; and (ii) difficulty in obtaining funding for specific research questions important to the public sector.

\section{Strengths of and challenges to trial conduct}

Participants identified the high disease prevalence and relatively strong infrastructure in the South African health system as being fundamental to potentially successful trial conduct in the country. Participants identified the lengthy MCC processes and complex logistics of RCTs, the high cost of trials and the potential burden of trial conduct on clinical care as major obstacles.

\section{Training and support needs}

Table I outlines the identified training and support needs, with research methods training a strong theme. Responses to needs for support structures were more diverse, with assistance with statistical analysis, data management and science writing emerging across the responses.

Participants were specifically asked if they believed that South Africa had sufficient and suitably experienced researchers able to conduct monitoring and quality control of RCTs. Of the 13 who expressed an opinion, 3 believed this to be true, 5 felt there were some suitably skilled researchers but insufficient for the need, and 5 stated that this was a major skills shortcoming.

\section{Need for a clinical trials support unit}

In 15 of 16 interviews, participants reported a need for an initiative at national level to encourage and improve the conduct of clinical trials. One interviewee stated that it should be focused on previously disadvantaged institutions; one stated that it should start small, and another stated that it should focus only on quality control and monitoring. Several participants expressed surprise that such an entity did not exist already.

Participants were asked to consider how such an entity would best operate and where its funding should come from. Four potential operational structures (Table II) and 4 key deliverables were identified: (i) provision of quality control, monitoring, and oversight of trials; (ii) training pertaining specifically to trials to avoid duplication with current university-based training programmes; (iii) mentoring support for the entire trial process from grant procurement to final report writing; and (iv) potential to play an advocacy role to streamline regulatory processes.

In 15 of the 16 interviews, representatives suggested that funding be derived from a national government source; specific recommendations included the MRC (5), DoH (2), Department of Education (1), Department of Science and Technology (1), national or provincial government with no departments specified (3), a combination of national departmental funding 
Table I. Training and support needs identified by participants

\begin{tabular}{ll}
\hline Training needs & Support needs \\
\hline - Good clinical practice & - Statistical analysis and management \\
- Research methods: general and specific to trials & - Quality control and monitoring \\
- Statistics & - Sata collection \\
- Epidemiology & - Ethics application and approval \\
- Pata management & - Negotiating the regulatory environment \\
- Protocol and grant writing & - Mentorship \\
- On-site training of field staff & - Patobase management \\
- Ethics training & - Guidance in using tax incentives (relevant to industry-led trials) \\
& - Project management \\
& - Funding procurement \\
\hline
\end{tabular}

\section{Table II. Proposed models of a national clinical trials support initiative}

\begin{tabular}{ll}
\hline Model & Structure \\
\hline Hub-and-spokes & $\begin{array}{l}\text { Unit is fully staffed and situated at a national centre, such as the MRC, and provides support and } \\
\text { training on an ad hoc basis to academic institutions, non-government organisations and research } \\
\text { councils conducting RCTs } \\
\text { Gollaborative }\end{array}$ \\
& $\begin{array}{l}\text { Administration and management of the collaboration is in a central site, either in one of the } \\
\text { academic institutions or at a national centre }\end{array}$ \\
Virtual & Groups, individuals within academic departments, and those based at research councils work \\
& together in a consortium, but no central site exists \\
& Communication is done electronically \\
& A website is administered with training tools and on-line support divided according to the \\
& strengths of the member groups \\
& Administration and supervision is done by one of the academic departments \\
No central site exists; any available national funding is directly allocated to a university \\
Extramural unit within university \\
department to establish an internal trials unit
\end{tabular}

(3), and the pharmaceutical industry in partnership with the $\mathrm{DoH}$ (1). One respondent recommended that trial sponsors including international agencies should contribute funds for establishing such an entity.

Many participants appeared dispirited by the apparent lack of long-term sustainability of such an initiative, some citing previous failed attempts at national collaborative projects, and cautioning about the potential for competition rather than collaboration between institutions.

\section{Discussion}

South African clinical trial research community senior stakeholders and decision-makers voiced the significant need for a national clinical trials initiative to support and enhance the conduct of public sector RCTs. Participants agreed that, ideally, the national government should provide specific funding to establish this initiative, and that its long-term sustainability should be carefully considered.

Kahn and Gastrow estimate that industry turnover in clinical trials run by the South African pharmaceutical industry is worth around R14.1 billion annually. ${ }^{9}$ Despite this, they argue that South Africa neither has the requisite human resources to be competitive internationally, nor does it invest enough. They report that increased trial activity could be attracted to South Africa by our well-established credentials in medical research, the high burden of disease and relatively drug-naïve populations. These factors were recognised by our participants as key reasons for conducting trials locally. Recommendations for a more proactive regulatory environment were echoed in our respondents' complaints regarding MCC waiting times and requests for assistance in negotiating the regulatory processes.

Most participants described the difficult local conditions facing trial investigators. Conducting trials within communities where literacy and health care knowledge of participants and providers is poor, has led to speculation that trials of high methodological quality are not possible within these settings. ${ }^{10-12}$ A comparison of African and North American HIV/AIDS RCTs found that the reported methodological quality of African trials was better than that of North American trials, independent of the country of residence of the principal investigator, ${ }^{13}$ which is encouraging for the future of local trial conduct.

Qualitative research was appropriate as it helps the development of concepts, giving emphasis to the meanings, experiences and views of all participants. ${ }^{14}$ Individual interviews allowed detailed exploration of the issues ${ }^{15}$ and provided rich, comprehensive data ${ }^{16}$ which might not have been achieved with a survey-driven approach. Consistency was ensured by each interview being conducted by NS. Interviews took place over a 4-month period to maximise availability of the appropriate institutional key informants. All but one of the pre-specified institutions were represented in the final sample. 


\section{Limitations}

The study is subject to limitations inherent in qualitative research. ${ }^{15}$ It was funded and conducted by the MRC, which has an interest in the location of such a unit, which might have influenced the investigators' interpretation of results. Participants working in government departments may be far removed from the 'coalface', and their comments may not accurately reflect needs. However, given the consistency of comments from all participants, this does not seem to have been a major limiting factor. Perhaps most limiting were the voices missing from this study, notably a stakeholder from the MCC. Feasibility issues prohibited a larger study, but opinions of more clinical investigators and of trial participants, civil society groups and community representatives would have enriched the study. Such studies could be key outputs of a future clinical trials unit.

We thank the interview participants for their time, Leon van Wyk for his excellent transcriptions, and Joy Oliver and Elizabeth Pienaar of the South African Cochrane Centre for their administrative support, assistance and enthusiasm. Nandi Siegfried acknowledges the support of the University of Cape Town's Research Office and the Department of Public Health for funding her attendance at a writers' workshop.

Conflict of interest. All authors are employees of the MRC, which funded this research.

\section{References}

1. Anonymous. Fifty years of randomised controlled trials. BMJ 1998; 317: 7167.

2. Gevers W. Clinical research in South Africa: a core asset under pressure. Lancet 2009; 374(9692): 760-762

3. Pang T, Lansang MA, Haines A. Brain drain and health professionals. BMJ 2002; 324(7336): 499-500.

4. Benatar S, Vaughan C. Global and local forces shaping the research agenda and the governance of research ethics. South African Journal of Science 2008; 104: 439-442.

5. MBewu A. How academic medicine should be positioned within medicine in Africa? A global perspective. In: Golden Jubilee of the Colleges of Medicine of South Africa. Cape Town: Colleges of Medicine of South Africa, 2005.

6. Department of Health. 2008/9 Annual Report. http://www.doh.gov.za/docs/reports-f.htm (accessed 14 October 2009).

7. Schulz KF. Unbiased research and the human spirit: the challenges of randomized controlled trials. CMAJ 1995; 153(6): 783-786.

8. Gluud C, Sorensen TI. New developments in the conduct and management of multi-center trials: an international review of clinical trial units. Fundam Clin Pharmacol 1995; 9(3): 284-289. 9. Kahn M, Gastrow M. Pharmacologically active: clinical trials and the pharmaceutical industry. S Afr Med J 2008; 98(2): 114-116.

10. Edejer TT. North-South research partnerships: the ethics of carrying out research in developing countries. $B M J$ 1999; 319: 438-441.

11. Enabling research in developing countries (editorial). Lancet 2000; 356: 1043.

12. Langer A, Diaz-Olavarrieta C, Berdichevsky K, Villar J. Why is research from developing countries underrepresented in international health literature, and what can be done about it? Bull World Health Org 2004; 82(10): 802-803.

13. Siegfried N, Clarke M, Volmink J, Van der Merwe L. African HIV/AIDS trials are more likely to report adequate allocation concealment and random generation than North American trials. PloS ONE 2008; 3(10): e3491.

14. Pope C, Mays N. Qualitative research: Reaching the parts other methods cannot reach: an introduction to qualitative methods in health and health services research. BMJ 1995; 311 : $42-45$.

15. Britten N. Qualitative research: Qualitative interviews in medical research. $B M J 1995 ; 311$ : 251-253.

16. Mays N, Pope C. Qualitative research: Rigour and qualitative research. BMJ 1995; 311: 109-

Accepted 22 January 2010. 